\title{
Single Nostril- A New Finding in the Phenotypic Spectrum of Schinzel Giedion Syndrome
}

\author{
BEGUM SHARIFUN NAHER ${ }^{1}$, ATM SHAHID ${ }^{2}$, MD. KAMRULAHSAN KHAN ${ }^{3}$, SHAHANA NARGIS ${ }^{4}$, \\ ABDUL HAI ${ }^{5}$, MD. MONIMUL HOQUE
}

\section{Introduction}

Schinzel Giedion syndrome (SGS) first described in 1978 , is a rare syndrome characterized by midface retraction, Choanal stenosis, prominent forehead, multiple skeletal anomalies, hypertrichosis, cardiac, renal and genital malformation $^{1}$. Till July, 2003, more than 30 cases have been reported in the literature ${ }^{2}$. Craniofacial abnormalities of the syndrome sometimes resemble a storage or metabolic disease, but patients with SGS do not have a biochemical abnormality ${ }^{3,4}$. Multiple skeletal anomalies include wormian bones in the skull with extension of metopic suture upto the nasal route. So there is high and protruding forehead. In the limbs talipcs equinovarus, polydactyly, hypoplasia of distal phalanges may be found.' Because of midface retraction nose is short with depressed nasal bridge and anteverted nares. Choanal stenosis may be present ${ }^{2,5-8}$. Regarding genital abnormality short penis, hypoplastic scrotum, hypospadius in males and hypoplasia of labia majora or minora, hymenal atresia in females are very common ${ }^{1}$. Hydronephrosis is considered as the clue for the diagnosis of this syndrome $e^{2,5}$. The pathogenesis of the disease remains unknown. No genetic marker is available. Autosomal recessive inheritance is likely based on documentation of one instance of affected child born to unaffected parents. Severe postnatal growth deficiency, profound mental retardation and seizure as well as visual and hearing problems may happen to those who survive ${ }^{3}$.

1. Assistant Professor, Department of Paediatrics SSMC \& Mitford Hospital

2. Assistant Registrar, Department of Paediatrics, SMC \& Mitford Hospital

3. Assistant Registrar, Department of Paediatrics, SSMC \& Mitford Hospital

4. Medical Officer, Department of Paediatrics, SSMC \& Mitford Hospital

5. Medical Officer, Department of Paediatrics, SSMC \& Mitford Hospital

6. Professor and Head of the Department of Paediatrics, SSMC \& Mitford Hospital, Dhaka

Correspondence: Dr. Begum Sharifun Naher

\section{Case Report}

A 2 hour old male infant, $4^{\text {th }}$ issue of a consanguineous parents hailing from Howly, Keraniganj, Dhaka was admitted in the hospital with the complaints of respiratory distress since birth. His gestational age was 30 weeks according to the last menstrual period. Mother did not have any antenatal check up. Baby was delivered normally at Mitford Hospital. Baby was moderately asphyxiated at birth (Apgar score 6/10 at 1 minute). He was resuscitated with bag and mask ventilation. His birth weight was $1600 \mathrm{gm}$ (below 90th centile), length 42 $\mathrm{cm}$ (middle of $50-90^{\text {th }}$ centile), occipitofrontal circumference was $33.5 \mathrm{~cm}$ (above $90^{\text {th }}$ centile) (macrocephaly) (Fig.-1). His face was dysmorphic characterized by prominent forehead, depressed nasal bridge, single nostril (Fig.-2) and microphthalmia, micrognathia. On palpation, skull was soft with wide fontanelle. All over the skull there were many wormian bones. In the left hand there was preaxial polydactyly (Fig.-3). Talipes equinovarus was evident on the same sided foot (Fig.-4). Bilateral cryptorchidism, hypoplastic scrotum and micropenis $(0.5 \mathrm{~cm})$ was remarkable (Fig.-5). He was tachypneic, $1^{\text {st }}$ and $2^{\text {nd }}$ heart sounds were normal and audible in all cardiac areas. Faint cardiac murmur was heard in the left parasternal area of the precordium but there was no cyanosis. On palpation of the abdomen it was soft, liver was just palpable and kidneys were not ballotable. His provisional diagnosis was multiple congenital anomaly with preterm and low birth weight. Baby was managed with intravenous fluid (10\% dextrose in baby saline). Inj. Ampicillin and inj. Gentamycin was used. He was kept in radient warmer with oxygen inhalation. After observing single nostril, we tried to introduce nasogastric tube inside but failed. Probably there was some sort of obstruction like choanal stenosis behind. The baby expired on the day of admission. So no investigation could be performed due to short time and limited facility. For this reason, on the basis of clinical findings he was diagnosed as a case of Schinzel Giedion syndrome. 


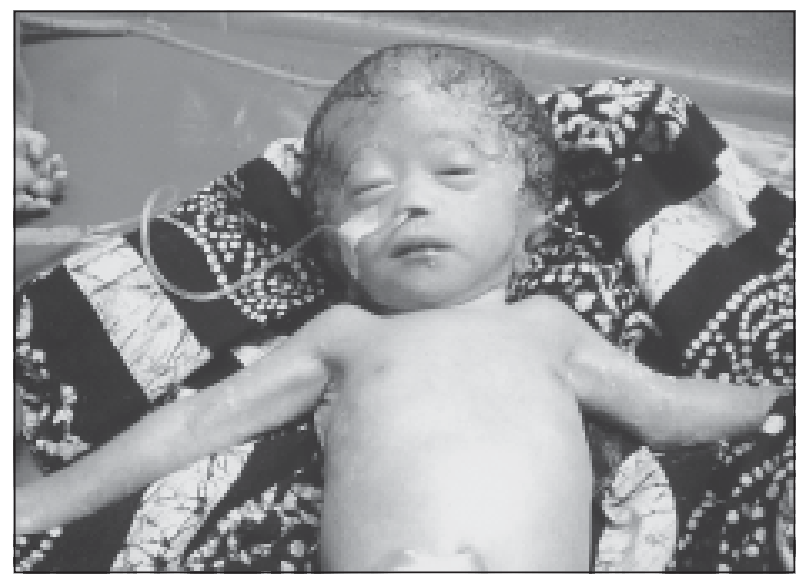

Fig.-1: Macrocephaly

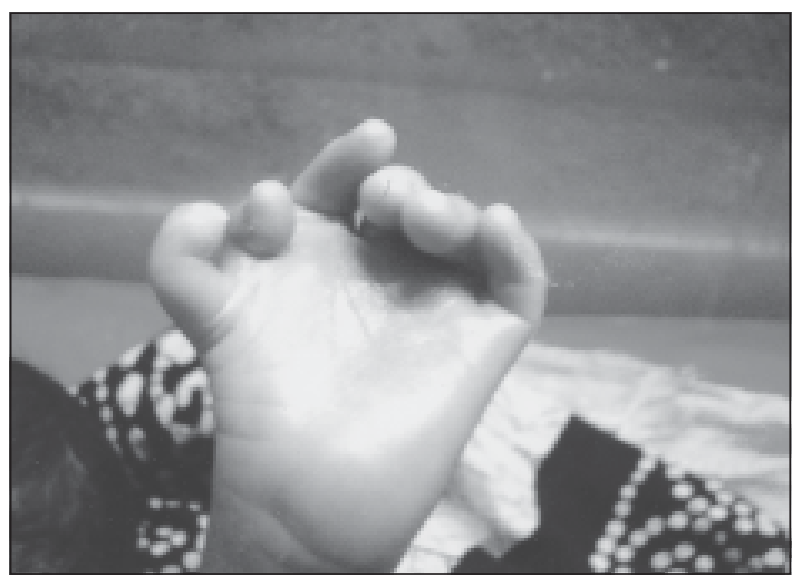

Fig.-3: Preaxial Polydactyly

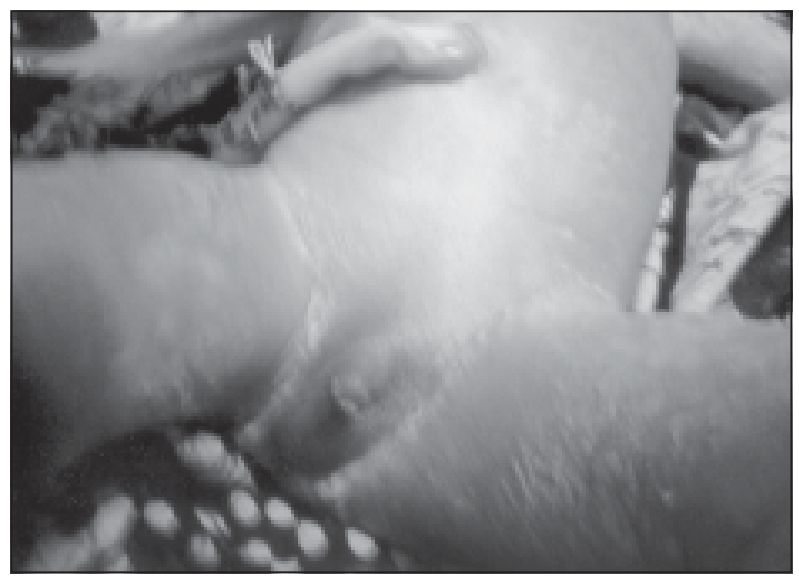

Fig.-5: Bilateral cryptorchidism, hypoplastic scrotum and micropenis

\section{Discussion}

The phenotypic characterization of Schinzel Giedion syndrome (SGS) includes a coarse midface retraction, a prominent forehead, wide anterior fontanelle/sutures, hypertelorism, low nasal root and low set ear. Hypertrichosis is another important external feature

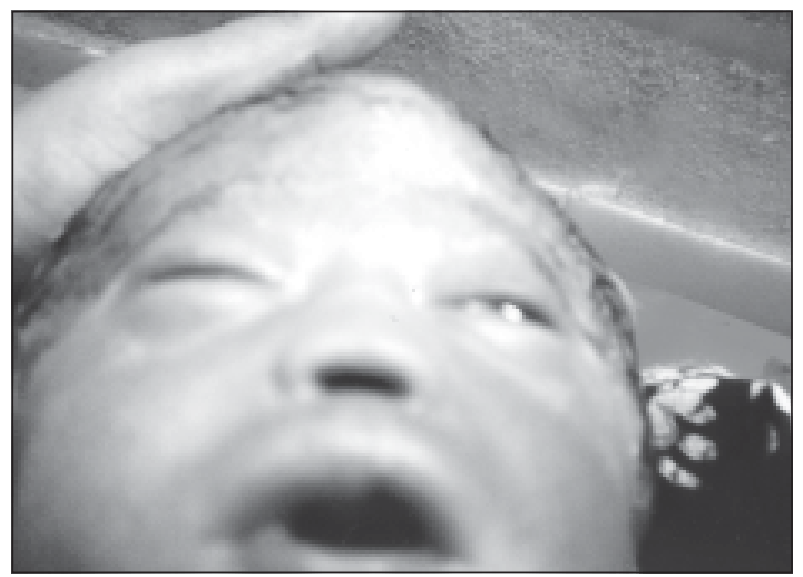

Fig.-2: Single Nostril

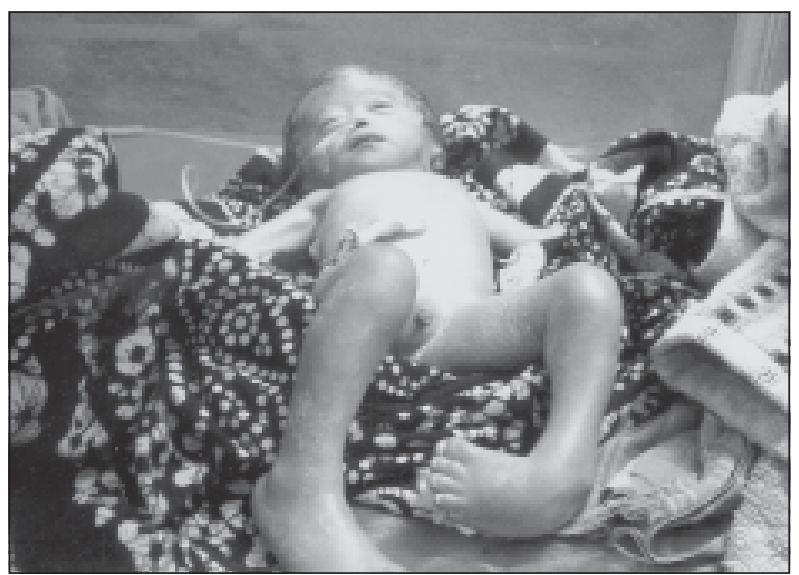

Fig.-4 : Telipes equinovarus

which disappears and midface retraction becomes less evident with age ${ }^{3-5}$. Structural abnormalities may be genital, renal, cardiac and nasal. Hypoplastic genitalia, micropenis in genital system, choanal stenosis with short and squared nose with anteverted nares, depressed nasal bridge are found. Cardiac evaluation usually shows patent ductus arteriosus, pulmonary stenosis, right ventriculer hypoplasia, intraatrial septal defect and mitral valve insufficiency ${ }^{9}$. Unfortunately in our case in spite of presence of murmur on the precordium echocardiography could not be performed because the baby expired at 3 hours after admission. Togue et $\mathrm{al}^{2}$ reviewed 35 SGS cases where he found presence of hydronephrosis in 31 cases. Minn et $\mathrm{al}^{5}$ have the same opinion. Kelly et $\mathrm{al}^{3}$ considered that the syndrome identification would be greatly facilitated if the SGS were indexed as a cause of congenital hydronephrosis. Though hydronephrosis is an important clue for the diagnosis of SGS, unfortunately due to nonavailability of portable ultrasonography in our facility, we could not find it 
out. USG during pregnancy was not performed which could have informed us about foetal renal pathology. Multiple skeletal anomalies are the characteristic finding in SGS. There are postaxial polycactyly, large thumb and great toe with lateral deviation, talipes equinovarus. In our case preaxial polydactyly was seen. The candidate gene of the disease has not yet been identified and diagnosis is strictly based on clinical findings. On the other hand patients with SGS do not have a biochemical abnormality ${ }^{3-4}$. So, more patients should be reported in order to amplify the phenotypic spectrum of SGS as has been recommended in the report of Albeno ${ }^{9}$. In addition to all findings so far highlighted in all available articles and case reports, 'single nostril' as a finding in Schinzel Giedion syndrome is not yet been published.

\section{Conclusion}

To strengthen the rapid diagnosis of SGS by clinical finding only in any set up like SSMC \& Mitford Hospital; we emphasize that the single nostril is a new and additional finding in the phenotypic spectrum of the syndrome.

\section{References}

1. Kenneth Lyons Jones. Smith's Recognizable Patterns of Human Malformation. $5^{\text {th }}$ edition. Philadelphia: WB Saunders Company; 1997.

2. Touge H, Fujnaga T, Okuda M. Schinzel Giedion syndrome. Intern J Urol 2002; 8: 237-41.
3. Kelley R I, Zackai E H, Charney EB. Congenital hydronephrosis, skeletal dysplasia, and severe developmental retardation: the Schinzel Giedion syndrome. J Pediatr 1982; 100: 943-46.

4. Al Gazali LI, Farndon P, Burn J. The Schinzel Giedion syndrome. J Med Genet 1990; 27: 42-47.

5. Minn D, Christmann D, De Saint- Martin A. Further clinical and sensorial delineation of Schinzel- Giedion syndrome: report of two cases. Am J Med Genet 2002; 109: 211-17.

6. Shah AM, Smith MF, Griffiths PD. Schinzel Giedion syndrome: evidence for a neurodegenerative process. Am J Med Genet 1999; 82: 344-47.

7. Labrune P, Lyonnet S, Zupan V, Imbert MC, Goutieres F, Hubert P, et al. Three new cases of the Schinzel Giedion Syndrome and review of the literature. Am J Med Genet 1994; 50: 90-93.

8. Shelagh J, Dean JCS. A Schinzel Giedion like syndrome - a milder version or a separate condition. Clin Dysmorphol 2002; 11: 271-75.

9. Albano LMJ, Sakae PPO, Mataloun MMGB, Leone CR, Debora R. Hydronephrosis in Schinzel Giedion Syndrome; an important clue for the diagnosis. Rev Hosp Clin Fac Med S Paulo 2004; 59: 89-92. 